\title{
RASTROS DE INOMINADOS. ARTE NARRATIVA E FANTASIA OBJETIVA EM VESTÍGIOS, DE ERNST BLOCH
}

\author{
Miguel Vedda ${ }^{1}$
}

\begin{abstract}
Resumo:
$\mathrm{O}$ artigo situa tematicamente e evidencia a atualidade da obra Vestígios (Spuren) de Ernst Bloch. Escrita de modo narrativo, nesta obra podem ser percebidas afinidades com autores como J. L. Borges, W. Benjamin, S. Krakauer ou mesmo G. Lukács. É por meio de contos que Bloch indica para a importância daquilo que é exterior e desconhecido ao sujeito, ou seja, daquilo que não se adequa a uma ratio sistematizadora, para a formação e transformação do próprio sujeito e da sociedade. São histórias que, por seus conteúdos excedentes, levam para além das narrativas em si, resistindo à manipulação mercadológica. Vestígios de tesouros utópicos e conteúdos emancipatórios que questionam a validez do mundo tal como ele se apresenta, sugerindo a superação da miséria real e do trabalho alienado, causados pela manipulação ideológica e a exploração material. Sinais de outro mundo possível, de outro paradigma de vida e sociedade: mais adequadas às potencialidades pessoais e sociais do que aquelas oferecidas pela sociedade capitalista. Ampliam-se, assim, as possibilidades de luta e de superação dos osbstáculos que impedem o desenvolvimento de potenciais já latentes no ser humano e na sociedade. (Resumo elaborado pelos editores).
\end{abstract}

Palavras-chave: arte narrativa. Resistência. Sociedade futura.

\section{TRAILS OF NAMELESS. NARRATIVE ART AND OBJECTIVE FANTASY IN TRACES, BY ERNST BLOCH}

\begin{abstract}
:
The article highlights and puts thematically into context the relevance of Ernst Bloch's work Traces [Spuren]. Written in a narrative way, affinities with authors such as J. L. Borges, W. Benjamin, S. Krakauer or even G. Lukács can be perceived in this work. It is through tales that Bloch indicates for the importance of what is external and unknown to the subject, that is, what is not suitable for a systematizing ratio, for the formation and transformation of the subject itself and society. These are stories that, due to their surplus content, go beyond the narratives themselves, resisting market logic manipulation. Traces of utopian treasures and emancipatory contents that question the validity of the world as it appears, suggesting the overcoming of real misery and alienated labor, caused by ideological manipulation and material exploitation. Signs of another possible world, another paradigm of life and society: better suited to the personal and social potential than those offered by capitalist society. Thus, the possibilities of struggle and overcoming obstacles that block the development of potentials already latent in human beings and in society are enlarged (Abstract drawn up by the editors).
\end{abstract}

Keywords: Future society. Narrative art. Resistance.

1 É professor titular de Literatura Alemã na Faculdade de Filosofía e Letras, da Universidade de Buenos Aires (UBA) onde é coordenador da cátedra livre "Teoria crítica e marxismo ocidental". Também é investigador do Conicet (Consejo Nacional de Investigaciones Científicas y Técnicas). Membro do Conselho de Redação de Herramienta, da Internationale Georg-Lukács-Gesellschaft e do NIEP-Marx (Núcleo Interdisciplinar de Estudos e Pesquisas sobre Marx e o Marxismo). (Nota dos editores). 


\section{RASTROS DE INNOMINADOS. ARTE NARRATIVO Y FANTASÍA OBJETIVA EN HUELLAS, DE ERNST BLOCH}

Podría iniciar este comentario con una insidiosa referencia al aquí y ahora en el que tiene lugar esta lectura de Bloch: un lector argentino que, como el autor de este artículo, se proponga hoy leer Huellas, no podrá dejar de encontrar llamativas las ostensibles afinidades que el volumen de fragmentos presenta con la narrativa de Borges. Ellas se advierten en aspectos tan variados como la fascinación por la narrativa detectivesca y la fantástica, por Las mil y una noches y la mística hebrea; la recurrente apelación al motivo de la máscara, la búsqueda de la propia identidad y el cuestionamiento de las naderías de la personalidad; la preferencia por los personajes anónimos y marginales; la devoción por objetos simbólicos dotados de un poder de seducción irresistible y desprovistos de valor mercantil; la pasión por el viaje. En este contexto no ha de resultar llamativo que el filósofo alemán y el escritor argentino coincidan en la reescritura de una misma historia, con sugestivas variaciones: nos referimos a la del hombre que sueña con un tesoro sepultado en una región distante, que sale de viaje para apropiárselo y que reconoce, gracias al viaje, que el tesoro se encontraba en verdad enterrado bajo el piso de su propia casa. Aún más importante que la elección de una misma materia narrativa es la operación de reescritura, que cumple una función capital en ambos autores; a propósito de los cuentos que integran Historia universal de la infamia escribió Borges que ellos son "el irresponsable juego de un tímido que no se animó a escribir cuentos y que se distrajo en falsear y tergiversar (sin justificación estética alguna vez) ajenas historias" (Borges, 2007, p. 343). Estas mismas palabras podrían aplicarse a las piezas de Huellas, cuyo autor se dedicó asimismo a pacer en jardines ajenos; solo que las flores robadas, sustraídas a sus contextos originarios e insertas en otro diferente, asumen de manera inesperada rasgos blochianos: se convierten en ilustraciones de aspectos distintivos de la filosofía del autor. Así, en la narración citada, el pobre hambriento y desempleado que parte en busca de un tesoro que, según la voz del sueño, se halla enterrado bajo los pilares del Puente Viejo de Praga, y quien al final de su travesía descubre que la riqueza está oculta en el propio hogar, evoca uno de los tema centrales del pensamiento de Bloch: la convicción en que el camino de formación del sujeto requiere abandonar la reclusión inerte en la interioridad y -como los héroes de los cuentos maravillosos de los hermanos Grimm- salir a recorrer el ancho mundo, no solo para ampliar su experiencia examinando a este, sino también a fin de acceder al conocimiento cabal de sí

\begin{tabular}{|l|l|l|l|l|}
\hline Qovista Dialeatus & Ano 10 & n. 21 & Janeiro - Abril 2021 & p. 162-175 \\
\hline
\end{tabular}


mismo. Arno Münster ha escrito que, en Bloch, viajar es "medio para conocerse mejor a sí mismo en la medida en que se observa más claramente el mundo, zonas geográficas, ciudades y hombres diferentes. Los senderos del viaje son estaciones de los caminos por el mundo externo tras las huellas del 'encuentro universal consigo mismo"' (Münster, 1982, p. 229). Acordes con tales perspectivas son las críticas al regodeo en la soledad o la delectación en el ocio reglamentado del capitalismo, que, como afirma Bloch, "no es una huida del trabajo, sino otra modalidad del trabajo" (2005, p. 89); detrás de estas dos formas ineficaces de evasión encuentra el autor de Rastros la misma raíz oculta: “Ambas, ociosidad y soledad, contienen un veneno de preparado químico, aunque la ociosidad nunca llegue a cumplirse. Este es el veneno de la oscura interioridad" (Bloch, 2005, p. 88).

Para Bloch, nadie está más lejos de encontrar su propia identidad que aquel que permanece sedentariamente afincado en el punto de origen; en cambio, lo que "se halla lejos de nosotros y está totalmente al margen de nuestra propia situación es más apto para reflejarnos o delatarnos que lo cercano" (2005, p. 95). De lo que se trata es de eludir lo inmediato e inerte: de aquello a lo que el Lukács de Historia y conciencia de clase, bajo la influencia de Bloch, denominó "la inmediatez de la cotidianidad irreflexiva" (Lukács, 1985 II, p. 25) y que el autor de Espíritu de la utopía denominaba oscuridad del momento vivido. Ese desplazamiento respecto de la inmediatez que marca el inicio de la odisea de la subjetividad, se conecta con una de las convicciones más hondas de Bloch, la de que todo ser (Sein) es, al mismo tiempo, un no ser: un no (Nicht) que, según se lee en la Tübinger Einleitung in die Philosophie (Introducción a la filosofía de Tübingen), es "carencia de algo e igualmente huida de esa carencia; es impulso hacia aquello que le falta. Con el 'no' se representa, pues, el impulso en el ser vivo: como impulso, necesidad, aspiración y, primariamente, como hambre" (Bloch, 1996, p. 218). La temprana intuición de este concepto del hombre en cuanto proceso es lo que sobre todo admira Bloch en Aristóteles, en quien no encuentra al árido fundador de la lógica formal y de la doctrina de las categorías, sino al pensador que afirmaba que todo organismo, partiendo de su realidad inmediata, aspira a la concreción de sus posibilidades, y que entendía que un rasgo esencial de todo ser el hecho de encontrarse continuamente en movimiento (cf. Horster, 1987, p. 12). La condena de las concepciones estáticas, mecánicas de la realidad atraviesa toda la obra blochiana; se expresa tanto en la crítica de la ciencia entendida como legitimación del statu quo, cuanto como vimos- en la aversión al conformismo y al ideal de vida placentera propiciados por

\begin{tabular}{|l|l|l|l|l|}
\hline Qovista Dialectus & Ano 10 & n. 21 & Janeiro-Abril 2021 & p. 162-175 \\
\hline
\end{tabular}


el capitalismo tardío. Frente a tales modelos, Bloch afirma siempre la preeminencia de la propensión a lo desconocido y a la aventura; de ahí que, al capitalista sedentario y consumista de la era del imperialismo, el filósofo oponga la versátil audacia que había caracterizado al burgués conquistador de comienzos de la Modernidad.

Estas posiciones de principio emergen en Huellas lejos de la abstracción a menudo enigmática de la Tübinger Einleitung o de Experimentum Mundi; asoman en cuentos maravillosos, historias de calendario, narraciones jasídicas, relatos fantásticos o simplemente anécdotas que muestran el inmarcesible poder sugestivo del acto de narrar, bajo circunstancias históricas en que dicho acto parece encontrarse en peligro. Se ha indicado la proximidad de Huellas al Benjamin de Calle de dirección única. Pero no menos importante es otra cercanía menos estudiada: aquella en la que la compilación blochiana se halla respecto de la obra ensayística del joven Kracauer, quien, por lo demás, dedicó a Huellas una aguda reseña. Es sabido que la teoría blochiana del fascismo está en deuda con las ideas de Kracauer; y, de hecho, las reflexiones de Erbschaft dieser Zeit (Herencia de esta época) sobre la Alemania de Hitler están pobladas de referencias a Los empleados. Pero las semejanzas con la obra ensayística kracaueriana se perciben ya con nitidez en Huellas; por ejemplo, en el interés por las personas extraterritoriales, es decir: hacia aquellos individuos que llevan una existencia nómada, no institucional en los márgenes de la Modernidad capitalista desprovistos de poder económico y ascendiente social, pero dotados de una sorpresiva capacidad para sacar a la luz y cuestionar la falacia del orden vigente. Encarnaciones ejemplares de semejante extraterritorialidad encontramos tanto en el protagonista de la primera novela de Kracauer -Ginster, muy celebrada por Bloch- como en la serie de artistas y personajes predilectos del ensayista frankfurtiano: Kafka, Offenbach, el Schweik de Hašek, el Schlemihl de la cultura hebrea, el vagabundo de Chaplin. En Huellas, este papel es desempeñado por seres que llevan una existencia antigregaria, contrapuesta con la rutina de los pequeños empleados de clase media. Uno de los más destacados es el payaso August, cuya forma de vida es la del "don nadie, el nobody":

Él no tenía una profesión prosaica como la de juez o la de jefe de ventas con la que sería mucho más importante de lo que era. Él pertenecía mucho más a la gente errante y también poco notoria y poco tenida en cuenta, esa gente que disfruta en muy pocas ocasiones de la leche y la miel. Ellos se arrastran, hacen piruetas y acrobacias en los límites de eso que el burgués llama el pueblecillo de los artistas, el pueblecillo de los que no llevan una vida monótona (Bloch, 2005, p. 103).

\section{Q Rovista Dialectus}

Ano 10 n. 21
Janeiro - Abril 2021 
A diferencia de los grandes burgueses y los burócratas de las clases medias, que creen ser alguien en virtud de la posesión de una fortuna o un cargo, August no tiene una identidad fija e inerte. Esto lo ilustra un accidente de trabajo que se detiene a narrar Bloch: cuando, en el curso de una función, el domador le pregunta quién es, en lugar de la respuesta rutinaria August "no solo perdió el hilo, sino también la conciencia de sí mismo. Empezó a tambalearse, se envolvió en sus propios brazos y empezó a susurrar con una voz distorsionada: 'No lo sé, no lo sé, no lo sé'” (Bloch, 2005, p. 102). El efecto que esta vacilación tiene en el público se asimila - como varias de las historias de Huellas - a lo siniestro freudiano:

Aquel señor Nadie calló ante el honorable público y la titulada nobleza circundante dejó de reír hasta que quien había perdido el nombre gritó en esta ocasión aturdido: no, yo soy un payaso y mi nombre es Augusto el tonto. Las lágrimas empezaron a caerle por el rostro, la vida cotidiana y la vida de todas las noches se había adueñado de él (ibíd.).

La admiración del autor de Huellas no se dirige -borgeanamente- al que "tiene un buen puesto, y en consecuencia un buen nombre", sino al "innominado oculto" que está latente en cada sujeto y que, si hiciera realidad efectiva, haría de este una personalidad más noble. Algo de esto vemos en Ginster, el protagonista de la primera novela de Kracauer, quien dice acerca de sí mismo:

\footnotetext{
Me devané los sesos ya a menudo [...] pensando sobre en qué me diferencio de los demás. Las personas están interesadas en sus vidas, tienen objetivos, quieren tener posesiones y alcanzar algo. Cada persona que conozco es una fortaleza. Yo no quiero nada. No me entenderá, pero preferiría diluirme como el agua. Esto hace que las personas estén lejos de mí. Duermo en un cuarto sin interés y ni siquiera tengo una biblioteca (Kracauer, 2004, p.131-2).
}

Otro rasgo que el Bloch de Huellas comparte con el autor de Ginster es la atención detectivesca hacia las cosas pequeñas y en apariencia insignificantes, aquellas que escapan al trabajo sistematizador de la ratio. Kracauer creía que en el mundo de las cosas reside un potencial revolucionario que reclama toda la atención del crítico (cf. Butzer, 2009, p. 159); el programa de redención de la realidad física recorre su íntegra producción, desde los escritos de mediados de los años veinte hasta Teoría del filme y el tratado póstumo sobre la historia. Adorno ha escrito que, en Kracauer, el estado de feliz inocencia

\begin{tabular}{|l|l|l|l|l|}
\hline Qovista Dialactus & Ano 10 & n. 21 & Janeiro - Abril 2021 & p. $162-175$ \\
\hline
\end{tabular}


infantil sería "el de las cosas menesterosas, las miserables, despreciadas, alienadas de su propósito; solo ellas encarnan, para la conciencia de Kracauer, lo que sería diferente del complejo funcional universal" (Adorno, 200, p. 392). Las pequeñas cosas son, en el orden de la materia, el equivalente de los individuos marginales en el orden social: elementos aparentemente accesorios en los que reside un potencial crítico considerable. Que esta devoción por las cosas pequeñas es común a Kracauer y a Benjamin es algo que subraya Agard cuando dice que ambos pensadores comparten el interés por "lo pequeño, por los detalles; es decir, también, por lo que está al margen de la tradición, por las causas perdidas, por las víctimas, por aquello que habría podido acontecer" (Agard, 2008, p. 143). Cabría añadir a estos dos nombres el del Bloch de Huellas, tal como lo testimonia la sección "Cosas" y, en particular, el fragmento "La espalda de las cosas", en el que se interroga acerca de la existencia que los objetos poseen al margen de la mirada que sobre ellos arroja el ser humano: "De un modo sencillo e ingenuo, preguntemos: ¿qué hacen las cosas sin nuestro concurso?, ¿qué aspecto tiene el cuarto cuando se lo abandona" (2005, p. 143). El hecho de que el narrador del fragmento recurra a relatos fantásticos para abordar la cuestión delata, en primera instancia, el empeño en enfrentar el desencantamiento del mundo propio del proceso de racionalización capitalista (cf. Münster, 2004, p. 149) oponiendo, a la estrechez de miras del "individuo promedio" -el Babbitt pequeñoburgués-, una mirada extrañada sobre las cosas, libre de estupidez utilitarista. De esta disposición crítica procede la invitación a pensar sobre la espalda de las cosas:

\begin{abstract}
Adelante todo está claro o ha sido esclarecido, pero ningún ser humano sabe en qué consiste la espalda de las cosas, de las que solo vemos la parte de abajo, y en las que se desdibuja el todo. Solo se conoce la parte de adelante, o la de arriba, de su obsequiosidad, de su amistosa incorporación a la comunidad; nadie sabe además si el idilio (a menudo preservado) de las cosas, su atracción, su belleza natural es lo que promete o lo que pretende retener (Bloch, 2000, p. 174-5). ${ }^{2}$
\end{abstract}

Pero, en segundo lugar, se trata de eludir una relación con los objetos que los reduzca a mercancías confortables que, en cuanto tales, reclaman una disposición pasiva, consumista. Esto es proyectado también a la experiencia de lectura que el autor espera para su propio libro; Bloch querría que los lectores de Huellas se enfrenten con historias provocativas, incapaces de promover un cómodo adormecimiento. En términos de Brecht, el

2 A diferencia de lo que ocurre con otros pasajes, en este preferimos ofrecer una traducción propia.

\begin{tabular}{|l|l|l|l|l|}
\hline Qonista Dialectus & Ano 10 & n. 21 & Janeiro - Abril 2021 & p. 162 - 175 \\
\hline
\end{tabular}


efecto buscado no es el de un arte ilusionista, culinario. Los lectores de Cortázar recordarán al personaje del marco narrativo de "Continuidad de los parques" que, una vez resueltas las cuestiones de negocios, se sienta "en la tranquilidad del estudio", a leer una novela con disposición evasiva, de modo que "la ilusión novelesca lo ganó casi en seguida. Gozaba del placer casi perverso de irse desgajando línea a línea de lo que lo rodeaba, y sentir a la vez que su cabeza descansaba cómodamente en el terciopelo del alto respaldo" (Cortázar, 2004, p. 417). El personaje va sumergiéndose en una historia que cuenta acerca de la ejecución de un asesinato y descubre por fin, en las últimas líneas del cuento que leemos, que la víctima del crimen planeado en la narración enmarcada es el propio lector de la novela. En Huellas asistimos tanto a la delectación en una narración cautivante como a una crítica a los efectos de la lectura pasiva comparable con la que veíamos en Cortazar. En conversación con José Marchand comenta Bloch, sobre las historias incluidas en Huellas, que hay que distinguir

dos clases de pequeñas experiencias personales e historias y aun historias de calendario. Unas están conformadas de tal modo que son leídas hasta el final confortablemente, en la cama, en la noche, antes de dormir. La historia ha concluido, todo ha quedado resuelto, uno apaga la luz y duerme el sueño de los justos, aunque no exista ninguno. Pero hay historias que no quedan concluidas cuando se las ha terminado de narrar; historias que tienen un excedente [...] que hace posible la interpretación de esa historia. Hay una huella de algo, y una huella al estilo de una historia del salvaje Oeste, al estilo de Cooper, Karl May y Gestäcker (Münster, 1977, p. 57-8.).

Las narraciones más efectivas de Huellas son aquellas que encierran una huella tal: una señal o una advertencia que rompe con las certezas del lector, que inquieta a este y lo instiga a seguir reflexionando, a problematizar no solo la historia leída, sino las propias condiciones de existencia. Bloch concibe este excedente como un aguijón o espina (Stachel) que hiere al lector, que le estorba la recepción indolente:

\footnotetext{
Aquí algo se mueve, o continúa moviéndose, de modo que uno no apaga simplemente la lámpara de la mesa de luz, se acuesta cómodamente de costado y se duerme contento, sino que algo ha producido un rasguño, es una espina en la historia. La espina es, naturalmente, aún más clara cuando nos afecta de manera inmediata y no solo a nuestro pensamiento (ibíd.: p. 60).
}

De lo que se trata es de épater le petit bourgeois, a quien la propaganda capitalista le ha inculcado la idea de que la felicidad consiste en rodearse de objetos destinados a

\begin{tabular}{|l|l|l|l|l|}
\hline Q & Ano 10 & n. 21 & Janeiro - Abril 2021 & p. $162-175$ \\
\hline
\end{tabular}


garantizar una vida estúpidamente placentera. El autor de Huellas busca oponerse al proceso por el cual la vida "ha colonizado las cosas, como si estas fueran objetos que no necesitan ni aire para respirar ni alimento, están muertos sin corromperse y siempre está a nuestra mano [...]. Sobre la espalda de estas cosas, como si fuera el más apropiado mirador, se ha asentado la cultura" (Bloch, 2005, p. 144-5). Uno de los propósitos de Bloch es mostrar, por las vías de lo extraño o de lo fantástico, la resistencia de los objetos a ser manipulados como mercancías. Este procedimiento muestra semejanzas con los que aplica Kracauer en relación con la materia inanimada; así, por ejemplo, en la sección "Dinge" (Cosas) de Straßen in Berlin und anderswo (Calles en Berlín y en otros lugares), o de un modo acaso más claro en su novela Ginster. Benjamin se refirió a la importancia de los objetos de utilería (Requisiten), que en las obras del Barroco alemán asumen una vida propia, independiente de los personajes. De un modo análogo, en la novela de Kracauer las cosas poseen una vitalidad de la que se ven privados los caracteres; así, Ginster se ve acosado por el mobiliario de su cuarto de estudiante: "Los objetos, que en general eran invisibles, emergían de su escondite y lo encerraban. Lo asustaba el lavamanos, los estantes laterales eran barreras" (Kracauer, 2004, p. 15). Propio de una estética de lo siniestro, pero a la vez saturado de ironía se encuentra el episodio en que Ginster se siente perseguido por un castillo barroco, al que solo con dificultad consigue sustraerse: "Dio la vuelta, agotado, perseguido por el castillo, que se esforzaba en meterse por los intersticios de las callejuelas. También los libros lo acosaban; se propuso no volver leer Poesía y verdad a raíz de la espléndida juventud del poeta, que él odiaba tanto como a la fachada" (ibíd.: p. 43). La certificación del Dr. Oppeln que Ginster presenta en la revisión médica parece también dotada de vida: "Sin estar totalmente desplegado, el papel migró desde la mano del médico a la mesa" (ibíd.: p. 90), y algo semejante ocurre con los anteojos de la tía, que "se diferenciaban de los demás por el hecho de que se le escapaban y aparecían en lugares en los que ella jamás habría sospechado que se encontraran: en la cocina, en el vestíbulo, incluso en el baño" (ibíd.: p. 138). No menos irónicos que este pasaje son aquellos en que la personificación se realiza con el fin de mostrar que, en la sociedad de masas, los individuos han quedado reducidos a funciones; por ejemplo, cuando se dice, mediante una eficaz metonimia, que, en el comando de distrito, los "uniformes hablaban, sin prestar atención a la gente, que se habían colocado a cierta distancia" (ibíd.: p. 144). En un mundo en el que las personas se ven "cercadas por sus cosas como por hiedra" (ibíd.: p. 218), es comprensible que los objetos asuman

\begin{tabular}{|l|l|l|l|l|}
\hline Qovista Dialectus & Ano 10 & n. 21 & Janeiro - Abril 2021 & p. 162-175 \\
\hline
\end{tabular}


"el hábito de cambiar espontáneamente de lugar", y demanden "una atención continua" (ibíd.: p. 165).

Hemos dicho ya que uno de los blancos de Spuren es el rutinario convencionalismo de la vida laboral y del ocio de las clases medias: un mundo que penetró como explorador Kracauer durante la segunda mitad de la década de 1920 como en un territorio desconocido y cuya inspección, según se lee al comienzo de Los empleados, "es quizás más riesgosa que viajar por África para rodar un film” (Kracauer, 2008, p. 116). Lúcidamente examina Kracauer la vida de los empleados burocráticos como una alternancia entre la experiencia de la miseria real en el trabajo alienado y la búsqueda de esplendor a través de una fuga de imágenes que no es, en el fondo, más que una fuga ante la revolución y la muerte:

En el Lunapark, de vez en cuando se exhibe, por la noche, una fuente iluminada con luces de bengala. Una y otra vez surcan la oscuridad haces rojos, amarillos y verdes. Una vez que se ha extinguido el brillo, se hace evidente que este provenía de la pobre forma cartilaginosa de algunos tubitos. La fuente se parece a la vida de muchos empleados. Esta se salva de su mezquindad en la dispersión; accede a ser iluminada por luces de bengala y se disuelve, sin tener conciencia de su origen, en el vacío de la noche (2008, p. 216).

Igualmente, consciente es Bloch de que lo que buscan las clases medias es perderse en el laberinto de las apariencias para no tener que examinar los fundamentos que se hallan detrás de ellas. Si el "sistema económico dominante", como dice Kracauer, "no quiere que calen sus intenciones" (2008, p. 158), es necesario colocar sobre él máscaras que distraigan respecto de lo esencial. El método de Bloch, como el de Kracauer, consiste en descifrar las marcas de lo visible a fin de descubrir una verdad sedimentada. En Huellas, lo visible -y aquí se advierten afinidades con la metodología benjaminiana- se presenta como una engañosa apariencia bajo la cual se oculta a menudo algo terrible que se trata de escamotear ideológicamente y que, como lo psicológicamente reprimido, necesita ser sacado a la superficie por el analista. Como muestras ejemplares de este examen de la dialéctica de apariencia y esencia valen la anécdota en que un espléndido asado deja escapar, en cuanto el tenedor se clava en la carne, un reguero de pus; o las reflexiones del narrador del fragmento "Saludos y apariencia", que no observa en los edificios que rodean la plaza la idílica calma aparente, sino -con además balzaciano y kracaueriano- los crímenes que en ellos se cometieron y que la conciencia convencional ha olvidado. Pero (y aquí adverti-

\begin{tabular}{|l|l|l|l|l|}
\hline Qovista Dialectus & Ano 10 & n. 21 & Janeiro - Abril 2021 & p. 162-175 \\
\hline
\end{tabular}


mos un motivo ausente en Kracauer, pero importante en el autor de Calle de dirección úni$c a$ ) existen también apariencias terribles, que encubren contenidos utópicos sepultados. La perspectiva blochiana parte de la convicción de que los hombres viven, bajo el capitalismo, en medio de un infierno en apariencia inmodificable que se revelaría susceptible de transformación si se consiguiera observar tras las apariencias. Este razonamiento recuerda aquello que Benjamin denominaba la irrealidad de la desesperación (Unwirklichkeit der Verzweiflung); como en Benjamin, también en Bloch aquel que desee acceder a esos contenidos emancipadores enterrados debería proceder como el arqueólogo que busca sus tesoros en las entrañas de la Tierra y no se demora en la superficie. Recuerda esto aquella construcción inversa a la que hace referencia Bloch en relación con varias narraciones de Huellas:

\footnotetext{
Podría compararse esto con el Palacio Ducal en Venecia, donde abajo, en la planta baja [...] aparece el ornamento (las arcadas) y arriba están los muros, en lugar de encontrarse abajo los muros y arriba el esplendor ricamente adornado en el que se extiende la construcción poética. Tenemos aquí un fundamento poético y no solo poético, sino también enfocado a los sueños, a los sueños diurnos, y arriba comienza el muro (Münster, 1977, p. 60).
}

Hay en esta especificación puntos en común con el método propuesto por Benjamin, para quien el trabajo del historiador se asemeja al del geólogo que desciende hasta las capas más profundas del terreno, o al del arqueólogo que desentierra los tesoros del pasado. En el proyecto sobre los pasajes, el París decimonónico es considerado como una fantasmagoría moderna que hunde sus raíces en una densa red de catacumbas y galerías subterráneas, en la que Benjamin advierte afinidades con el Hades mítico; idéntico aspecto revelan las bocas del Métro "cuando, en la noche se encienden las luces rojas que muestran el camino hacia el Hades de los nombres" (Benjamin, 1991 I, p. 135). No menos importante es el hecho de que el laberinto de las ciudades sea comparado con la conciencia: un dédalo de casas en que, en lugares ocultos, se insinúan lugares de acceso a los infiernos, los que, a su vez, están "llenos de lugares inapreciables en que maduran los sueños” (ibíd.). Idéntica búsqueda de lo utópico reprimido encontramos en Huellas, aunque ellas se amalgaman con elementos típicamente blochianos; entre ellos, la idea de que la íntegra realidad existente es una mentira, y que, frente a ella, tiene un valor aun ontológicamente superior el pensamiento utópico. Esta convicción -uno de los aspectos más equívocos de la filosofía de Bloch- es eficaz como un recurso estético y retórico orientado a mostrar, de manera pa-

\begin{tabular}{|l|l|l|l|l|}
\hline Qovista Dialectus & Ano 10 & n. 21 & Janeiro - Abril 2021 & p. $162-175$ \\
\hline
\end{tabular}


recida al extrañamiento brechtiano, la invalidez de una realidad degradada que las clases medias aceptan como la única valida. Como el hombre de campo que, en la leyenda kafkiana, se sienta dócilmente a esperar el permiso para acceder a la ley y que va petrificándose en su inmovilidad, los pequeños empleados "se acostumbran a este pellejo en el cual no solo son metidos, sino en el que se los ha metido, profesionalmente o de otra manera" (Bloch, 2005, p. 37). Frente a esta mentira que representa el mundo vigente, ciertas imposturas -como aquellas en las que consiste, en última instancia, la literatura- poseen un grado más alto de verdad. De ahí la función que poseen en el libro aquellos impostores que, a diferencia de las figuras despreciables del arribista y el parvenu, se colocan la máscara de una identidad aristocrática -falsos príncipes o condes- porque no aceptan que sea auténtica la condición alienada en la que viven, y que terminan creyendo en la autenticidad de su impostura. Esta fantasía es la continuación, en la vida adulta, del sueño de convertirse en príncipe que alienta en las lecturas infantiles de cuentos maravillosos; de acuerdo con Bloch, la mayoría de los hombres no son al comienzo demasiado, sino demasiado poco respecto de aquello en lo que finalmente se convierten. A partir de esto se siguen es posible desarrollar dos reflexiones. Por un lado, el rechazo de todas las circunstancias en que, como decía Marx, el hombre es un ser humillado, esclavizado, abandonado, despreciable; y la búsqueda de una identidad aparentemente falsa y esencialmente auténtica se vincula tanto con el principio de la dignidad humana -al que dedica Bloch un análisis detallado en el conocido libro de 1961-, sino también con la conciencia anticipadora. En El principio esperanza, Bloch afirmará, en contra de la tesis freudiana según la cual los sueños diurnos son solo fantasías infantiles revestidas de un yo adulto, que el sujeto de tales sueños

\footnotetext{
está penetrado de la voluntad consciente, siempre consciente, aunque en grado diverso, hacia una vida mejor, y el héroe de los sueños diurnos es siempre la propia persona adulta. Cuando César contempla en Gades la columna de Alejandro en pleno sueño diurno y exclama: "Cuarenta años y no he hecho aún nada para la inmortalidad”, el ego que reaccionaba así no era el del César niño, sino el del César hombre; más aún, el del César futuro (Bloch, 1977, p. 67).
}

A propósito de la identificación, no con el yo empírico, sino con el posible, se dice en Huellas que no hay ningún ascenso a esferas superiores que se produzca sin una defensa del propio valor, que no es verdadero, o que aún no es verdadero: "El joven músico Beethoven, quien de repente creía y afirmaba ser un genio sin par, se comportaba como un tipo extrañísimo de impostor al pretenderse igual a Ludwig van Beethoven, quien, a fin

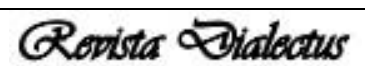

\section{Ano 10 n. 21}

Janeiro - Abril 2021 
de cuentas, todavía no era" (Bloch, 2005, p. 44). Pero, por otra parte, con esto se relaciona una reflexión sobre las formas de lucha contra el capitalismo que posee plena vigencia. Un núcleo central dentro del marxismo cálido promovido por Bloch en cuanto correctivo para las tendencias economicistas, positivistas es el imperativo de combatir contra lo que en Erbschaft dieser Zeit es designado como la "desnutrición de la fantasía socialista". En las tendencias hegemónicas en el marxismo de los años veinte y treinta advertía Bloch un cientificismo árido que, en su falta de seducción para la conciencia de las masas, dejó a estas en manos de la propaganda nazi. En el fragmento "El grillo molesto", el personaje que mejor defiende las perspectivas blochianas ataca tanto la deformación economicista del marxismo como la idealización de las condiciones de vida empíricas del proletariado. El proletario actual "muchas veces solo es un pequeñoburgués fracasado, se pasa a un partido populista o al grupo de poseedores de un pequeño negocio que se sientan en un canapé rojo" (Bloch, 2005, p. 35). Cualquier "culto del proletariado es falso y está infectado de burguesía" (Bloch, 2005, p. 36); por lo tanto, no se trata de idealizar a la clase obrera como un modelo de existencia envidiable, sino de pensar en una realidad que aún no existe y que es deseable, e incluso necesario hacer realidad. Esto existe hoy, para el pensamiento y la praxis marxistas, como un desafío: la caída del gris socialismo real y la del modelo de socialismo en el que él se sustentaba se debe en buena medida a su incapacidad para presentar ante los hombres un modelo de existencia más apetecible que el que ofrece el capitalismo. De lo que se trata, entonces, es de configurar a este como una visión del mundo y, a la vez, como un paradigma de vida; en esto posee una importancia decisiva la exhortación blochiana para investigar cómo podrían ser la sociedad futura y el hombre nuevo. Esto tiene implicancias para la vida de los individuos y sus propias posibilidades personales de lucha en contra de la explotación material y la manipulación ideológica. De acuerdo con el autor de Huellas, la formación auténtica exige combatir con todos los obstáculos que impiden el desarrollo de una personalidad latente y superior. Una anécdota muy conocida de Picasso podría sonar como una suerte de síntesis del pensamiento blochiano en este aspecto. Se cuenta que el pintor español dijo en una ocasión: "Cuando yo era pequeño mi madre me decía: 'Si te haces soldado llegarás a general; si te haces monje, llegarás a ser Papa'. En cambio de todo eso decidí ser pintor y me convertí en Picasso" (Gilot/Lake, 1982, p. 45). Estas palabras bien podrían haber funcionado como epígrafe de Huellas.

\section{Qovista Dialectus}

Ano 10 n. 21
Janeiro - Abril 2021 


\section{Referências}

ADORNO, Theodor W. El curioso realista. In: Notas sobre literatura. Obra completa, 11. Traducción de Alfredo Brotons Muñoz. Madrid: Akal, 2003, p. 372-392.

AgARD, Olivier. Les éléments d'autobiographie intellectuelle. In: DESPOIX, Philippe y SCHÖTtLER, Peter (comps.), Siegfried Kracauer. Penseur de l'histoire. París, Montréal: Maison des Sciences de L'Homme, 2008, p. 141-163.

Benjamin, Walter. Gesammelte Schriften V. Das Passagen-Werk. Ed. por Rolf Tiedemann y Hermann Schweppenhäuser con la colaboración de Theodor W. Adorno y Gershom Scholem. 2 vols. Frankfurt/M: Suhrkamp, 1991.

BLOCH, Ernst. El principio esperanza [1954-1959]. Trad. de Felipe González Vicén. Vol. I. Madrid: Aguilar, 1977.

BLOCH, Ernst. Tübinger Einleitung in die Philosophie. Frankfurt/M: Suhrkamp, 1996.

BLOCH, Ernst. Spuren. Frankfurt/M: Suhrkamp, 2000.

BLOCH, Ernst. Huellas [1930]. Pról. de José Jiménez. Trad. y notas de Miguel Salmerón. Madrid: Alianza, 2005.

BORGES, Jorge Luis. Obras completas I (1923-1949). Buenos Aires: Emecé, 2007.

ButZer, Günter. MedienRevolution. Zum utopischen Diskurs in den Meidentheorien Kracauers und Benjamins. In: GRUNERT, Frank y KIMMICH, Dorothee (eds.), Denken durch die Dinge. Siegfried Kracauer im Kontext. Múnich: Fink, 2009, p. 153-168.

Cortázar, Julio. Cuentos completos/1. Buenos Aires: Punto de Lectura, 2004.

GILOT, François; LaKe, Carlton. Leben mit Picasso. Zúrich: Diogenes, 1982.

HORSTER, Detlef. Bloch zur Einführung. 6a ed., totalm. revisada. Hamburgo: Junius, 1987.

KraCAUER, Siegfried. Werke. Ed. de Inka Mülder-Bach e Ingrid Belke. Vol. 7: Romane und Erzählungen. Ed. por Inka Mülder-Bach con la colab. de Sabine Biebl. Frankfurt a/M: Suhrkamp, 2004.

KraCAUER, Siegfried. Los empleados [1930]. Trad., postfacio y notas de Miguel Vedda. Barcelona: Gedisa, 2008.

LuKÁCS, György [1923]. Historia y conciencia de clase. Trad. de Manuel Sacristan. 2 vols. Buenos Aires: Hyspamérica, 1985.

MÜNSTER, Arno. Utopie, Messianismus und Apokalypse im Frühwerk von Ernst Bloch. Frankfurt/M: Suhrkamp, 1982.

\begin{tabular}{|l|l|l|l|l|}
\hline Q Rovista Dialectus & Ano 10 & n. 21 & Janeiro - Abril 2021 & p. $162-175$ \\
\hline
\end{tabular}


MÜNSTER, Arno. Ernst Bloch. Eine politische Biographie. Darmstadt: WBG, 2004.

MÜNSTER, Arno. (ed.). Tagträume vom aufrechten Gang. Sechs Interviews mit Ernst Bloch. Frankfurt/M: Suhrkamp, 1977.

ZuDEICK, Peter. Der Hintern des Teufels. Ernst Bloch - Leben und Werk. Moos \& Baden-Baden: Elster, 1987.

\begin{tabular}{|l|l|l|l|l|}
\hline Q Povista Qialectus & Ano 10 & n. 21 & Janeiro - Abril 2021 & p. $162-175$ \\
\hline
\end{tabular}

